\title{
GRACE FLAHIVE
}

\section{TITLE:}

\section{DIGITAL SELF-PROMOTION FOR THE} UNDERDOG AUTHOR: CREATIVE OPPORTUNITIES AND EXPERIMENTATION

\section{ABSTRACT}

This paper addresses a lack of originality in the online self-promotion of many mid-list, indie and self-published authors, investigating the strategies of authors who are making more creative use of digital technologies for their self-promotion. This research provides a practical point of guidance to other authors of fiction wishing to innovate in this way.

The literature review provides an overview of changes in global media consumption following the digital revolution. This research suggests that creative digital promotional projects might be a low-cost, high impact way of overcoming some of the resulting challenges.

Primary research is undertaken in the form of case studies, profiling three authors' promotional projects. The effectiveness of their projects is measured in terms of increased reader/author engagement, increased online visibility, book sales, and more.

The research finds that creative digital promotional projects are particularly successful if they are inventive, utilize online community-building, feel like a unique event, and can stand alone as digital or interactive art. It is also found that though these projects may not increase book sales directly, they have long-term positive impacts on the author brand. While requiring significant time commitment on the part of the author, an inventive, well-executed promotional project can be a comparatively low-cost way to differentiate oneself in a crowded marketplace. 


\section{LICENSE AGREEMENT:}

(C) 2017, this article is distributed under the terms of the Creative Commons Attribution License (CC-BY) 4.0 https://creativecommons.org/licenses/by/4.0/, which permits unrestricted use, distribution, and reproduction in any medium, provided the original author and source are credited.

\section{Article type:}

Research Article

\section{How to cite this article:}

Flahive, G. (2017) Digital self-promotion for the underdog author: creative opportunities and experimentation. Interscript Journal, 1-(2) pp.23-42. DOI: 10.14324/111. 2398-4732.002

DOI:

10.14324/111. 2398-4732.002

\section{Author affiliation:}

London College of Communication

\section{Competing interests:}

None

\section{First published:}

18th May 2017 


\section{Full Article}

\subsection{Aim and purpose}

This paper investigates the creative digital self- promotional strategies of a small number of fiction writers, from which is produced practical guidance. The researcher set out to interview a number of authors about the effectiveness of their digital strategies in boosting sales and public profile. The paper considers various unconventional digital projects that authors use to drive public awareness of their titles, asking how these strategies address common problems of discoverability, limited budget, sales and author/reader engagement. It also asks how might the effectiveness of these projects be assessed, in order to provide insight for authors wishing to undertake similar projects.

\subsection{Project scope}

This project will focus on contemporary authors of fiction, open to a variety of English-speaking areas, including the U.K., U.S. and Canada, in order to achieve diversity of studies. This investigation is interested in what will be termed the 'underdog' author, meaning those that stand at a disadvantage to blockbuster or brand name authors in terms of marketing and promotional support. For the purposes of this study, 'underdog' authors may include mid-list authors at medium to large sized publishers, authors at small or independent publishers, and self-published authors.

Whilst this category is difficult to define, it is important to note that the research does not conflate these different groups, nor presume that their situations are identical. However, it does proceed from the premise that authors of these kinds face similar challenges, and must likewise find solutions. These challenges are caused by forces that affect the industry at large, including changes in digital media consumption and a global shift towards digital culture.

\section{Context and Industry Overview}

\subsection{Introduction}

The rapid evolution of digital technologies has caused an upheaval in book publishing in recent years. As a result, the publishing industry has been forced to confront new challenges. This chapter will provide an overview of two of the most significant changes that have occurred in the publishing industry in recent years, and the implications of these for underdog authors.

\subsection{Publishing corporations}

With the rise of large publishing corporations, the market has become pillared by a small number of gargantuan powers. These corporations grew partly out of necessity, in response to changes in the retail environment in the last several decades. The inevitable result was a "wave of mergers and acquisitions" (Thompson 2012) that ate up smaller firms and contributed to the top-heavy distribution of power that exists today. By the 1990s, rather than many smaller, diverse houses, there were a small number of corporations each owning many imprints (2012).

Today, the UK market is dominated by the 'Big Five' who possess $50 \%$ of the market, with Penguin Random House alone owning 24\% (Mintel Oxygen 2014). Whilst this is not inherently negative, there is some wariness that these enormous companies cannot provide the nurturing, creative ethos of a smaller publisher. As Thompson describes it, "there are risks associated with the increasing size of publishing corporations, one of which is the danger that it will impinge on and damage the creative activities that lie at the heart of the publishing firm" (2012).

However, multi-billion dollar corporations, while achieving efficient economies of scale, may not be interested in smaller authors creating more literary or challenging work. In an increasingly homogenized trade book industry, underdog authors are at an even greater disadvantage than ever before. 


\subsection{Market-led publishing and the mid-list}

\section{crisis}

Intertwined with these organizational changes, new cultural and technological influences have impacted upon publishers' priorities. Books must now compete against an array of digital entertainment options in the fight for consumers' attention and disposable income (Baverstock 2008, Thompson 2012), forcing publishers to become more market-led (Mintel Oxygen 2014). As Penguin Random House Canada CEO, Brad Martin, declared this year, "I'm not interested... in a book that is going to generate less than $\$ 100,000$ in revenue unless the editor or publisher has a compelling vision for the book and/or the author". This reflects the industry attitude at large.

This has had a number of implications.

There is more pressure than ever to discover the next 'blockbuster' title, the sort of global bestseller than can spawn a book and film franchise and bolster revenues. Global brands such as Harry Potter, Twilight, The Hunger Games and Fifty Shades of Grey are common examples. But this practice is polarizing the industry. By Rankin's estimation, 4\% of titles now fund the remaining 96\% (2014).

This top-heavy distribution of resources means that mid-list authors are given less attention. While large promotional budgets are allotted for the small number of high-profile titles, mid-listers are left wanting, and are increasingly forced to take on a double role of writer and self-promoter.

In this age of instant blockbusters, there is also less patience for the slow and gradual growth of a smaller author. As Smith describes it, "belief in an author, as opposed to a particular book an author as a long-term investment - tends to exist less and less" (2015). Each individual book is given less time to prove itself on the market typically six weeks - before promotional resources are cut (Thompson 2012).

To add a final element to the challenge, the surge in online sales has secured the midlist author's plight. Whereas physical bookstores once provided these books with visibility, "Digital books create a retailing bypass that diminishes the exposure of midlist books to potential readers" (Morris 2010). Tools such as Amazon recommendations have attempted to replicate the serendipity of a bookstore, but these algorithms continually fail to turn up truly original and unexpected finds. More readers are turning online to purchase their print and digital books, making it arguably more likely that they will purchase from a small pool of 'smash hit' titles.

\subsection{The case of the self-published author}

Self-publishing has seen an unprecedented explosion with the rise of digital communications technologies. Whilst authors signed with publishers may receive some, if meagre, marketing support, self-published authors in most cases orchestrate all of their marketing and promotional efforts on their own, and a self-published author is perhaps the most free to embrace all promotional possibilities afforded by digital technologies.

The explosion of self-publishing afforded by digital technologies and services has transformed the relationship between writers and readers. Alex Pham quotes publishing consultant Mike Shatzkin, who explains, "Publishers used to be the gatekeepers... Going through the gate still has certain benefits, but it's no longer the only way for authors to get to where they want to go" (Pham, 2010). The internet has afforded writers new, non-traditional options, and dissolved many of the barriers between a creator and her audience.

With this power, however, comes greater responsibility. Once a book is formatted, uploaded and available for purchase online, all the effort of marketing and promotion remains in the hands of the author. An increasingly busy marketplace means self-published authors must work even harder to make their title known. Self-published titles in the U.S. alone increased by an estimated 442\% between 2007 and 2013, a figure that does not include books published without an ISBN (Bury 2013). Further study might be able to determine whether self-publishing authors are indeed more innovative in their digital promotion than those published traditionally. 


\subsection{Consequences and challenges for}

\section{authors}

The primary challenges for 'underdog' authors outlined include: limited resources; less time to prove one's worth in the market; and a saturated market increasing discoverability pressures. These three elements together produce a formidable challenge. How can underdog authors drive sales with such little financial support, when the market is saturated by more books than ever before? Effective low-cost self-promotion has never been a more crucial tool for authors than it is today. Any author not considered a marquee name must become increasingly nimble at promoting themselves effectively, with a clear strategy.

As the digital age produces a proliferation of titles and authors, the online landscape has become a cacophony of voices, all vying for readers' attention. Whilst social media platforms such as Facebook and Twitter are useful tools for the self-promoting author, with so many titles being promoted in the same manner, authors must differentiate themselves in order to be noticed.

This paper will highlight authors who are using digital technologies less conventionally (and arguably more creatively) for self-promotion, in order to drive awareness of their titles in a saturated market. It will now undertake a review of relevant literature in order to map the major issues and themes pertaining to this area, as a foundation for the primary research to follow.

\section{Literature Review}

\subsection{Online and Social Media Marketing:}

\section{Four characteristics}

With the rise of web communications, marketing and promotion has increasingly found a place online. Whilst traditional promotional methods such as print or television are far from dead, businesses now understand what a well-ex- ecuted online marketing campaign can do for their brand and products. This paper highlights four key characteristics of online or social media marketing as it exists today, which may be considered advantages:

\subsubsection{Global reach}

\subsubsection{Low cost}

\subsubsection{Targeting ability}

\subsubsection{Participation}

Perhaps the most notable feature of online or social media marketing is that it can reach a global audience instantly. With more than 3 billion web users worldwide (Internet Live Stats 2015) - including 1.44 billion active Facebook users and 236 million active Twitter users (Statista 2015) - the internet presents an audience of consumers larger than any other.

Social media sites offer businesses a platform through which to spread messages about their products, building their brand online and capturing the interest of users. This information is available to the consumer instantly, whilst mobile communications devices allow the scope of online marketing to penetrate the pockets of consumers worldwide (Sheehan 2010).

A second advantage of online and social media marketing is its comparatively low cost (Evans 2012). Social media profiles may be created free of charge, and marketing messages distributed instantly.

Some overhead or indirect costs must be considered, such as the salaries of the marketing managers who manage social media and costs for website hosting, maintenance, or the purchasing of unique domain names. However, compared to the costs of traditional promotional methods online marketing appears to be the least costly (Ryan and Jones 2009).

A third notable feature of online or social media marketing is its ability to target only the most relevant or most interested consumers (Sheehan 2010, Strugatz 2014, Thompson 2012). Through tools such as hashtags, search filters or relevant social media pages and groups, 
a business may target their marketing efforts to those most likely to be interested in their brand or product.

The internet is a rich web of online communities based around interest - "whether formally built around a specific interest or cause or informally built through more casual connections and the interactions between members" (Evans 2012). Users may be targeted based on a combination of interests or segments, allowing a business to target those most receptive to their marketing messages.

A fourth and final characteristic of online marketing is its emphasis on participation, shifting from broadcast to engagement. Whereas traditional marketing and promotional techniques broadcast a one-way message to a passive audience, marketing online can be a two-way street (Ryan and Jones 2009).

The ethos of social media in general is one of user engagement and participation.

Sites like Facebook, Twitter, and YouTube are built on the premise of users uploading, sharing, rating and commenting (Kietzmann 2011). It is principally an interactive process, and the same holds true for social media marketing. Brands must adapt to this process and use it to their advantage, fielding comments and reviews, and engaging in conversation with their consumers (Kaplan 2010).

The internet, and in particular social media sites like Facebook and Twitter, bring businesses and brands into a closer and more direct relationship with their customer than ever before (Ryan and Jones 2009). If harnessed effectively, this relationship can increase customer loyalty, improving products through instant customer feedback.

An indirect benefit of online marketing and promotion is the rich well of data that is made available to the business (Evans 2012). Teams can track the popularity of their marketing campaign through the use of related hashtags, the number of 'Shares' and 'Likes' on posts and pages, and related re-tweets and favourites. Some sites also offer in-depth insights into the number of engagements and users reached. Other helpful social media metrics may include data on "number of clicks, length of stay... repeat vis- itors" (Evans 2012). In other words, everything that is uncertain about the success of traditional advertisements is now measurable in real-time.

These instant insights allow the business to see which campaigns are working, which posts are catching the attention of users, and which pieces of content need to be reworked. Decisions can then be made on where best to allocate time and resources, at which times to share content, and the audience at which to aim. Online marketing, therefore, permits a dynamism and flexibility in planning and response that traditional print advertising does not allow.

\subsection{The "online presence": online and social media marketing for authors}

In the same way that the internet has become an indispensable promotional tool for businesses of all kinds, an 'online presence' is now considered nearly compulsory for authors. Many publishers and literary agents even consider an author's online self- promotional skills or fan base as a top priority before signing them to a deal (Kinberg).

The pressure to be present online, therefore, is stronger than ever.

The internet affords authors all the same promotional benefits that it affords businesses in general. Social media marketing is a low-cost, instant method of promotion that has a global reach, can target the most relevant consumers and can build up a well of user data.

\subsection{Branding}

Author branding is an increasingly popular strategy being used to differentiate authors on the market. It is useful to unpack the word 'brand' as it is used more broadly, in order to understand the advantages that might accompany author branding in particular. In business, the word "brand" refers to:

“...a customer experience represented by a collection of images and ideas; often, it refers to a 
symbol such as a name, logo, slogan, and design scheme”. (AMA 2014)

A brand gains its identity by differentiating itself from other brands or available products. It might do so on the basis of price, quality, design, or other factors (Liberman 2014) When promoting itself, a brand tries to emphasize its unique value - the value it can provide above other similar brands or products.

\subsubsection{Author brands}

Author branding is becoming an increasingly essential component of author self-promotion. It is considered one of the most effective methods of differentiating oneself from other authors and creating a memorable emotional connection with readers (Sargent 2014).

In terms of books, 'brand' most often refers to global book and film franchises like The Hunger Games and Fifty Shades of Grey. These sorts of mammoth brands spawn merchandising, stage adaptations and online worlds, expanding well beyond the original book series.

The word 'brand' may also be used to describe individual authors. This phenomenon is described by Marosevic, indicating that "a 'brand' is an author who sells in huge numbers and who secures blanket media coverage and fawning upon publication" (2014). She cites J.K. Rowling, Dan Brown and Gillian Flynn, author of Gone Girl, as examples.

The activity of branding is not exclusive to big-name authors, however. Even smaller authors can benefit from branding themselves, and there is increasingly a push to do so. The phenomenon of self-promotion and online branding is described very well when Liberman states:

"Just like brand managers highlight and communicate the qualities of certain products to appeal to consumers and potential consumers, so, too, do Facebook and LinkedIn users highlight and communicate qualities about themselves to appeal to both existing and potential network members" (2014).
In other words, an author can choose to take up branding themselves online, and to communicate a coordinated 'brand' message through the attributes they highlight about themselves or their work. The design of their website, tone of their tweets and Facebook posts, and content of their marketing messages all project the feeling or experience of their brand. In this sense they become their own brand ambassador (Liberman 2014).

An author, like all social media users, is "responsible for the social construction of their own image" and is "afforded the opportunity to create an identity rife with positive personal characteristics" (Liberman 2014). In other words, social media becomes a tool for constructing a positive brand image. Just as brands in business wish to differentiate themselves, so too does the author brand. They might do so on the basis of any number of distinguishing characteristics - a unique social media style, memorable fictional characters, a unifying design to book jackets, and so on.

When actively 'branding' oneself, online and social media are now channels through which to convey a particular, crafted customer experience. At a time when the market is saturated by more titles and authors than ever before, the advantages of a crafted author brand are obvious. The branded author may differentiate herself from the crowd, and make her unique value obvious, memorable and known.

\subsection{Creative digital promotion in}

\section{publishing and other industries}

As mentioned above, the internet is now considered crucial to marketing and promotional efforts across all industries. Websites and social media presences are increasingly indispensable tools for businesses of all kinds. While traditional methods remain important, digital technologies afford new opportunities for promoting products and forming strong customer relationships.

Despite this en masse online move, however, not all businesses use digital technologies as effectively as others. Most appear to simply 
'go through the motions', developing an online presence through basic social media sites. They then post news and product information through these channels. A study carried out by Millward Brown found that repetitive approaches like these are not working. According to their data, "looking at brands' pages, [users] want to see something new, fresh, or different - not a rehash of the same information they can get on a brand's official corporate homepage" (2011). The key, then, is uploading relevant and engaging content to catch the attention of the consumer.

The themes raised in this literature review drew a rather challenging picture of the contemporary underdog author. With little or no promotional budget, she must make her title stand out at a time when discoverability is an enormous challenge. This paper will suggest that creative digital promotional projects may be one solution to this multifaceted challenge. In response to the themes outlined in this review, the ideal project would:

- take full advantage of the four features of online marketing as outlined above;

- help in developing or reinforcing an author brand;

- allow for maximum exposure with minimum financial investment;

- differentiate the author and her works through innovative and memorable user experiences.

Using this literature review as a foundation, the paper will now move forward to primary research, in order to analyze author challenges and solutions in a real-life context.

\section{Research Design and Methodology}

\subsection{Research Objectives}

The objectives of this research project derive from the questions raised in Section. The objectives are as follows:

- To determine what unconventional digital projects are being used to drive awareness of underdog authors' titles;

- To assess the effectiveness of these projects using various measures - ex. online visibility, increased sales, etc;

- To determine how these projects address common problems of discoverability, limited budget, sales, and author/reader engagement;

- To provide practical guidance to other underdog authors wishing to continue in this creative vein.

\subsection{Research Methodology}

This project focuses on the strategies and creativity of individual authors. It seeks to highlight their specific projects as they have unfolded in the world, and to examine the subjective, creative processes involved. As such, a qualitative research methodology was deemed most appropriate for this project.

Davies states that:

"All qualitative research methods begin with the assertion that social researchers are located in a subjective context, and cannot lay claim to neutral or scientific objectivity” (2007).

Whilst quantitative research can be defined as an "objective, systematic process in which numerical data are used to obtain information about the world", this project aimed to collect anecdotal evidence, including subjective thoughts, stories and opinions (Burns 2005). While some quantitative data, such as sales and budgetary figures, became useful supplementary measurements in some cases, the research as a whole was undertaken from a qualitative framework. 


\subsection{Research Methods}

\subsubsection{Multiple case study}

The case study method was deemed most appropriate for this project, given that it investigates individual digital promotional projects, and would allow the researcher to "produce a rounded portrayal of an identified subject", meaning the selected project or projects (Davies 2007).

The project aims to show the diversity of creativity available to authors today. A multiple case study method was therefore chosen, allowing the research to highlight a number of projects. While multiple sources of evidence would improve the reliability of the results, the multiple case study method requires more time and labour than a single case (Yin 2009).

As the topic of creative digital self-promotion for small authors is fairly new, the researcher found that an "exploratory study" was the best approach (2009).

The selection of cases for the multiple case study was the next decision. Yin recommends that the researcher, "consider multiple cases as one would consider multiple experiments - that is, to follow a 'replication' design" (2009). In this instance, the researcher predicted a theoretical replication. While each case - i.e., each digital promotional project - would be subjected to the same study, each was also distinct. The results would likely be contrasting, because each project used different media and resources for different purposes.

The multiple case study method then required that each case study be conducted, and that findings be written up and compared. These steps are detailed in the following sections, and in the chapter Analysis of Research Findings.

\subsubsection{Interviews as data collection method}

The primary method of data collection was the interview. The researcher determined that interviews would be the best way to gain an indepth understanding of each project and the authors' motivations.
In order to source interview participants, the researcher undertook an extensive search for creative digital promotional projects of the desired type. She made contact with individual authors who were innovating in this field, and also reached out to British, American and Canadian publishers for author referrals (a list of all contacts made is included in Appendix A). Organizations such as The Society of Authors and The Alliance of Independent Authors also agreed to advertise the search on their social media pages.

Ultimately, however, the research was dependent upon which contacts replied, and which authors were available and willing to participate. In the end, the researcher was satisfied that the three selected interviewees were of quality, and represented an array of different creative promotional projects.

The questions asked in the interviews originated from the research questions and objectives. Apart from minor situational differences, the questions posed to each author were largely the same, in keeping with the "replication design" (Yin 2009) mentioned above. Most were open-ended, allowing the authors to respond freely and to offer new thoughts and insights (Yin 2009).

For reasons of scheduling and geographical distance, two of the three interviews took place via email. This posed some limitations, in the sense that the researcher and subject could not interact as freely as they might in a verbal or in-person interview.

However, the ultimate responses were extremely detailed and showed a great depth of thought on the part of the interviewed authors. The third interview was conducted via Skype, also due to geographical distance.

As with any interview, the responses were "subject to the common problems of bias, poor recall, and poor or inaccurate articulation" (Yin 2009). However, this weakness was balanced by including data from other sources as well (Yin 2009), i.e. from articles, real-life social media responses to the projects, and so on. 


\subsubsection{Data analysis}

The interview data was analysed using interpretive content analysis, and more specifically a coding scheme.

Following the primary interaction with the data, the researcher began the coding process. This involved identifying "the principle emergent ideas in each piece of transcripted data" (Davies 2007), in order to create "a coding frame, into which (most of) [the] accumulated data will gradually fit" (Davies 2007). In this case, the coding categories were developed inductively from the data (Zhang 2009), by reading through and pinpointing themes or ideas that recurred.

After rigorous analysis of the text, the codes were applied throughout, until every chunk of data had been assigned a code, using Microsoft Word comment tags on the Track Changes feature. This scheme was then checked for accuracy and consistency (Zhang), and was repeated rigorously for each set of interview data. Once all data had been analysed in this way, it was possible to "identify and reduce to manageable proportions the central themes that will drive [the] report" (Davies 2007).

\section{Analysis of Research Findings}

\subsection{Case \#1: Michael J. Seidlinger}

The first case to discuss is the "airport project" conceived of and carried out by author Michael J. Seidlinger to promote his novel The Fun We've Had. Information was gathered through an email interview with the author himself, as well as through online articles and social media responses to the project.

\section{The author and the project}

Michael J. Seidlinger is an American author, editor and publisher, who has released four novels with independent publisher Lazy Fascist Press (Portland). When considering promotion for his 2014 release The Fun We've Had, Seidlinger says he felt the need "to create something, DO something, to thematically celebrate" his book. He and a close friend, author Kyle Muntz, bought tickets for a JetBlue flight from John F. Kennedy International Airport. However, they did not the board the plane, instead remaining on the main concourse area of the airport for forty-eight hours, documenting the experience on social media. The airport setting was chosen intentionally, because its feelings of "in-betweenness" and liminality are themes of the novel.

\section{Analysis of interview findings}

The most common theme that emerged in Seidlinger's data was an emphasis on online dialogue and interaction, as social media users reacted and interacted with Seidlinger's and Muntz's documentation of their airport stay. The act of living in the airport was given second life on the digital platforms where updates, comments and anecdotes were shared between author and reader.

Seidlinger stated, “...moments after we began the $48 \mathrm{hr}$ period, I realized that I'd never be lonely-people kept in touch and truly connected via social media channels (...) They reached out and kept us entertained, remained around, tweeting, commenting, posting, feeling like they were really part of something". It is this sense of digital connectedness and community that was perhaps the largest strength of the project.

This community had great benefits for Seidlinger as an author, most notably an increase in online visibility for himself and his book. By tapping into an existing base of readers, Seidlinger enhanced and broadened this community as others joined the conversation. He cited an increase in Twitter followers and Facebook friend requests, and reported via his publisher that "the book sold at a solemn but consistent pace for weeks/months following the project". As well as his time, and that of his friend, the performance cost Seidlinger the price of the JetBlue ticket, which he quoted at “ $\$ 70-80$ ”, or about $£ 48$.

The project's benefits were not all direct or immediate. Seidlinger cites an article that he wrote for the website Electric Literature, documenting the project retrospectively (2014). The attention received by this article, along with delayed word-of-mouth gave the book "staying power", and "the 'legs' it needed to continue walking/selling over a year after launch".

The project's challenges included a constant 
pressure to continue posting entertaining, timely social media updates. There was also the physical exhaustion incurred from sleeping and living in the uncomfortable space, and the risk that social media would not catch on and the project would fall flat. However, these challenges appear to have been clearly overcome and outweighed by the promotional benefits of the project for both Seidlinger and his novel.

\subsection{Case \#2: Nikesh Shukla}

The second case in the multiple case study is the "lamb chop" project that author Nikesh Shukla conceived of and carried out to promote his novel Meatspace. Data was collected through a Skype interview with the author, as well as through the project video, social media responses and related online articles.

\section{The author and the project}

Nikesh Shukla is a British Indian novelist and television writer (Shukla 2015) who has published novels with both indie and mainstream publishers. His 2014 novel Meatspace was released by HarperCollins, who helped promote the book through traditional channels. Shukla, however, wanted to do something more inventive for the novel as well. He and a friend planned a stunt, inspired by a literal interpretation of the book's title, that would involve launching a piece of meat into space. A GoPro camera and a lamb chop were fastened to a weather balloon powered by helium. The launch and flight was thus filmed, while GPS technology was used to track the location of the lamb chop. The footage was then edited, uploaded online, and came to be shared widely, striking conversation on social media and raising awareness of the book.

\section{Analysis of interview findings}

The most common theme that emerged in the interview with Nikesh Shukla was an emphasis on creation and innovation. Social media is a prominent theme in the novel Meatspace itself, so Shukla knew a clever digital campaign would be essential.

The emphasis was on action, and the cre- ation of a memorable event. In his words, "We went completely outlandish with it."

This inventiveness was rewarded by an enormous online response. The edited video of the lamb chop's flight was uploaded, and quickly gained unprecedented attention. Shukla describes his Twitter 'mentions' at this time as "unmanageable", also stating that, "...it all happened so quickly... We didn't really expect the amount of coverage it got." The video has since been viewed nearly three hundred thousand times (YouTube 2015).

The project increased the book's visibility, both online and in real life. Shukla credits the project with revitalizing awareness of the title, which had been released earlier that year. But the effects were even more wide-reaching, as Shukla noted, "It also helped my career as a writer... it gave me a status".

Following the popularity of the video, Shukla was invited to appear at festivals, speak on panels and so on, allowing him an increased financial freedom as a writer. He describes the transformation, saying, "You know, before that I was just a writer with a mouthy presence on Twitter who had a couple of warmly received books out. But now I'm a writer that people seem to think of when they're programming things".

Shukla notes that the project's popularity did not correlate one-to-one with an increase in book sales. Rather, the effect was much more amorphous and indirect. He describes the phenomenon as "not tangible" but more of a "ripple effect", whereby these more frequent appearances at festivals and events had a positive "knockon" effect for book sales. Shukla invokes the language of author brands when he says the project acted as "the flyer" representing him as an author more broadly.

As well as his time, and that of his team members, the Meatspace lamb chop project cost Shukla three hundred pounds, including an unplanned fifty pounds rewarded to the farmer who found the camera pod. There were risks that the project would not go as planned. Shukla remarks himself that when he approached HarperCollins and told them of his idea, he understood that the stunt had "really high potential for failure". It was also not guaranteed that the video would 
spark the online attention that it did. However, given that everything went as planned, the project was incredibly beneficial to Shukla's career and the promotion of his book.

\subsection{Case \#3: Terri Giuliano Long}

The third case in the study is the Literary Road Trip project conceived of and conducted by author Terri Giuliano Long, promoting her novel In Leah's Wake. Data for this case was collected through an email interview with the author and her assistant Donna Brown, as well as through blog posts and articles documenting the project.

\section{The author and the project}

Terri Giuliano Long is an American self-published author, who has achieved extraordinary success in her field. Her novel In Leah's Wake reached sixth on the Barnes \& Noble Nook Top 100 list following its debut in 2011, and has since sold more than 130,000 copies (Giuliano Long 2015). She is at work on a second novel.

Despite this success, Giuliano Long must continue to manage marketing and self- promotion with limited resources, like any underdog author. To overcome this challenge, Giuliano Long and her assistant used the site Placing Literature, which allows users to map real-world locations from literature. Originally mapping In Leah's Wake, the pair then decided to expand the idea. In December 2013, they launched a one-month "virtual literary road trip" (Williams 2013) across the United States. Having mapped the locations in both her existing and upcoming novels, Giuliano Long also invited readers to submit their favourite places from literature, and contributed her own. Each day, she then showcased two locations on social media, each from a different state, following the Placing Literature map across the country. The pair have continued to stage virtual road trips, now expanded internationally.

\section{Analysis of interview findings}

The most common theme throughout the author's answers was an emphasis on communi- ty building. The participatory nature of the road trip project, and the encouragement to share locations, helped to build and expand a network of interested authors and readers. This network spread awareness of Giuliano Long's own titles, but she also stressed her commitment to promoting other authors in this way. As Brown explains:

"We are constantly building connections and part of that is being willing to cross promote and spread the word about other people's blogs and books. Many of the events we have run have had the main aim of building community".

The success of the virtual road trips can be measured in one sense through increased social media traffic - Brown cites Facebook, Twitter and Pinterest - at these times. There is also an increase in newsletter subscribers, and a rising interest in the continued giveaways related to the events. Brown is quick to point out the longer-term benefits, however, noting, "These events create content for the blog, which aids in SEO and people finding the blog in the future through searches and backlinks." This is similar to the effect that Seidlinger and Shukla cited regarding the online articles about their projects.

Much like the previous two case study authors, Giuliano Long explained that there was not a measurable correlation between book sales and the success of the project, remarking that often, "a project brings no immediate sale or financial gain. But, as Donna points out, we are building connections - and there is no way to accurately measure the immense value in this". She believes that promotion is a matter of "repeated images". When a reader is repeatedly exposed to the author's name in blogs or on social media, that author will remain in their mind, and improve the likelihood of sales. She concludes that for authors, "public image is equally or perhaps even more valuable than sales metrics."

An exact budget for the road trip projects was not cited, but Brown did point out the cost of her own services to Giuliano Long, as well as costs for such things as "graphics, online services, [and] prizes for giveaways". Time is equally as scarce as money, however. Both women pointed out that the time-consuming nature of the 
road trips was a huge challenge. These promotions must be balanced alongside ordinary social media maintenance, as well as Giuliano Long's writing time. The author felt a great deal of pressure in this sense, having to take time away for writing, without losing the engagement of her audience.

Overall, however, Giuliano Long feels that the literary road trips are worthwhile as a promotional tool. She says, "...these events are far more beneficial than draining. Events keep my name in front of people and, again, help us to continue building the network." These events allow repeated, positive exposure for the author across a large network, raising awareness of both herself and her titles in the minds of potential readers.

\subsection{Cross-Case Analysis: Guidance for Authors}

Having reviewed each case individually, it is now possible to analyze themes across all three cases. Discovering similarities between the authors' experiences will highlight the successful strategies adopted by the authors and the common problems they faced, and which characteristics of the projects made them successful promotional tools.

Six major themes were common across all three cases in the study, each functioning as a heading (to follow), which may act as a practical guide to other authors wishing to undertake promotional projects of this kind. They are by no means exhaustive, as they only represent the experiences of three authors, but together prove useful for such projects based on the studies undertaken.

\subsubsection{Be inventive}

All three authors expressed dissatisfaction with traditional methods of book promotion. Seidlinger described typical readings and book launches, saying "I find that sort of promotional treatment tired and ineffective. It just felt and continues to feel inert for me". He believes that doing something "fun and weird and insane" attracts a larger audience. Shukla, too, said that HarperCollins offered him great support with the more traditional promotional methods, such as blog and mainstream press reviews, however he felt most authors were lacking in terms of greater creativity. Giuliano Long, as well, notes a need for improvement, saying, "There are so many 'buy my book' tweets, emails and posts flying around that we try to ensure that our events are more creative".

All three projects began as simple, inventive ideas that had the potential to catch attention of a reader in a single sentence, whether "I'm going live in an airport for two days to promote my book" or "I'm staging a virtual summer vacation". They were inventive, striking and likely to be shared by word of mouth via social media, given their peculiarity and ability to be summarized in one line.

None of the ideas were complicated, nor necessarily required a large budget. They were simply inventive ideas, executed well, differentiating these authors and their titles from the crowd of authors all promoting in a similar, repetitive way.

\subsubsection{Engage or create a community}

All of the authors stressed the importance of an online community in the success of their projects. In Seidlinger's case, this was the Twitter users "who kept in touch and truly connected", acting as audience and participant in his airport performance, and in Shukla's, the online community that viewed and shared his lamb chop video, allowing it to go viral and spread awareness of his title. In the case of Giuliano Long, a community of authors and writers was both built and expanded throughout the literary road trip, with these same network members contributing locations for the event.

All authors cited an increased engagement between themselves and their readers. The projects encouraged a two-way interaction between the creator and the user, rather than the projection of a one-way promotional message. The interactions that took place as part of the projects, 
or as a result of them, created lasting reader/author relationships. This meant that the authors remained in the readers' minds long after the projects were over.

\subsubsection{Make the project feel like an event}

All of the projects were unique in the sense that they stood apart from the rest of the authors' ordinary promotion, and acted as an event. Seidlinger describes this, saying:

"They reached out and kept us entertained, remained around, tweeting, commenting, posting, feeling like they were really a part of something. That's magical and ultimately what I couldn't have ever anticipated--making the project feel like an actual event."

This feeling of the project being "special" or "one-time only" likely contributed to their popularity amongst intrigued readers and internet users. Each was a performance or display that would not normally be seen every day from that author, giving a special feeling to the project. Readers were proud to say that they had participated in, witnessed or contributed to something out of the ordinary. The clear distinction between the ordinary promotional efforts of the author and these projects added a level of excitement and intrigue that likely encouraged more users to share the news of the author and his or her titles.

\subsubsection{Make something that is able to}

\section{stand alone as art}

Related to the point above, each project was also able to stand alone as a piece of digital or interactive art. Seidlinger's airport project was in a sense performance art.

Shukla's lamb chop video can be appreciated as a humorous and fascinating clip in its own right. And Giuliano Long's road trips can be enjoyed as an interactive digital project, separate from the books it promotes.

Seidlinger again summarizes the idea well, saying:

"I think more of us should work on creating projects, inherently promotional, that act more like their own creations. The airport project was its own thing. It can stand on its own. The fact that it was done to promote a book was secondary. You could view it for what it is, outside of the book."

The projects were arguably strengthened by their ability to stand alone as art. This is likely because they acted as valuable, entertaining online content in their own right, giving the user enjoyment, rather than simply pushing them a promotional message.

\subsubsection{Remember that positive effects may not be directly measurable - long. \\ term positives are what is important}

All three authors remarked that the success of the projects could not be measured in a one-to-one correlation with book sales or other financial figures. All three authors experienced an increase in online visibility and engagement, however the positive impact of the projects was felt in a more indirect and amorphous way, and was often delayed.

Giuliano Long and her assistant called the relation between the project and sales "impossible to measure" but remarked that there was increased name recognition in the longer term. The project also built a network of readers and users who would act as an interested audience for future releases. Shukla's observations were similar, calling the impact of the project "not tangible in the slightest" but said that the project allowed him increased online visibility, and notoriety as a writer on the whole. Seidlinger calls the impact, "more of a residual effect", explaining that it "helped the book have staying power because, ironically, everyone had more of a delayed reaction to the project".

All three authors agreed that even when a project did not result in any direct or imme- 
diate financial gain, it had long-lasting positive impacts in other ways. These impacts included increased online visibility, increased awareness of their titles amongst new readers, increased name recognition, and a more prominent profile in the author community as a whole.

On a broad level, the projects delivered a positive, original message, and showed that these were authors capable of doing interesting things. They made it more likely for a reader to remember the name or title, causing a positive chain reaction with the potential to strengthen that author's career.

\subsubsection{Write an article or blog post about the project when it is finished}

All three of the authors wrote at least one article or blog post about their project when it was complete. For Seidlinger, this was his article remembering the airport project for Electric Literature, for Shukla this was his feature on Vice, and for Giuliano Long, this was a blog post on her on site, as well as a feature done by the Placing Literature blog. Documenting the project in this way allows future interested users to discover and resurrect it through sharing. As Giuliano Long points out, an article like this improves the online discoverability of the project. This then becomes useful for elongating the positive impact of the project. While the events or performances themselves may have been temporary, they can be solidified online, and experienced again and again by interested users who come across the article or video documentation.

\subsection{Possible risks, limitations and failings}

While the projects were determined to be extremely useful and positive promotional tools, they equally had limitations and failings. A list of possible failings or negative aspects has been compiled below, based on analysis of the interview findings.

\section{High investment of author's time}

While the ideas for the projects may have been simple, their execution required a significant time commitment from each author. Even Giuliano Long, who is able to employ an assistant, noted that time and resources were pinched during the events.

When an author must write in order to be paid, this is something serious to consider before planning a separate promotional project. Writing time, day jobs and ordinary promotion are all huge priorities, and an author must consider if they can spare the time to plan and execute a side project of this kind.

\section{Budgetary considerations}

None of the projects required an unreasonable amount of financial input on the part of the authors. However it would be naïve to think that all authors are able to contribute even small budgets of this kind. The financial limitations of mid-list, independent or self-published authors could therefore be a prohibitive factor. While social media promotion is free and can be done independently, these promotional projects involved extra elements or outside factors that brought financial costs. Admittedly, promotional projects of a similar nature would likely require a certain amount of disposable income that is not available to every author.

\section{Possibility of failure or poor response}

While these three projects were successful and received wide attention, there was no guarantee that the response would be so large. For example, Shukla was thrilled by the attention given to his video, but recognized before the project that it had "really high potential for failure". Seidlinger also voiced his doubts, saying:

"I was constantly anxious and nervous throughout the duration of the project, simply due to the transparency of the project and how quickly it could have fallen flat, ignored by everyone online."

There is no way to ensure that the project will be shared on social media, nor that it will receive notable attention of any kind. As the web is full of interesting, eye-catching content, even an

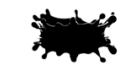


inventive project of quality is liable to be overlooked.

\section{Risk of poor execution}

These three projects were exceptionally executed, and engaged audiences in a way that enhanced the author's brand and online image. However, there is always a risk involved in performing or posting anything online. A poorly executed project could very easily damage an author's brand rather than enhance it. Users may perceive the project as a "gimmick", feel resentful of its promotional motives, and so on. There is always a risk that the project or content will alienate potential readers rather than draw them in.

\section{Conclusions and Recommendations}

\subsection{Conclusions}

This research was undertaken with the following objectives:

- To determine what unconventional digital projects are being used to drive awareness of underdog authors' titles

- To assess the effectiveness of these projects using various measures - ex. online visibility, increased sales, etc.

- To determine how these projects address common problems of discoverability, limited budget, sales, and author/reader engagement

- To provide practical guidance to other underdog authors wishing to continue in this creative vein

All three of the profiled projects met the characteristics outlined in the literature review. It was determined that creative digital promotional projects of this kind can be extremely effective tools for raising awareness of an author's titles, and increasing that author's public profile on the whole. A surprising or inventive idea, executed well, can differentiate an author and her titles from the swell of repetitive promotional material that floods the market today.

These projects can be wide-reaching, lowcost solutions for underdog authors facing chal- lenges of discoverability on a limited budget. While projects of this kind may not directly increase book sales, in all cases in this study, they had long-lasting positive impacts on the author's career. These included increased online visibility, a wider and more engaged online community, enhanced reputation, name recognition, and more. This sort of exposure can be invaluable to underdog authors who receive limited promotional support from their publishers, and as well as for those publishing independently.

\subsection{Recommendations for digital promotion}

This research began from a feeling of dissatisfaction in relation to the originality of most authors' digital promotion. This same sense of dissatisfaction was felt by all three case study authors, who urged for more risk-taking and inventiveness in promotional methods.

While the researcher was excited to find the three projects highlighted here, the research process and literature review uncovered despairingly few projects of this kind. In an attempt to unearth more, the researcher in fact found herself inventing digital projects which, unfortunately, did not exist. The strongest recommendation, then, is that underdog authors experiment more widely with their digital strategies.

Possibilities for experimentation are endless, but very few have been realized. The researcher suggests that authors take up a broader range of contemporary media forms, and exploit them in new and inventive ways. Beyond the requisite Twitter and Facebook, authors might experiment with Snapchat, Soundcloud, Wikipedia, Buzzfeed lists and quizzes, dating apps, and many more.

\subsection{Recommendations for further research}

1. As mentioned above, further research could be undertaken into the possible applications of digital art, digital interactive projects and transmedia storytelling for the purposes of book promotion. There is untapped potential here for 
innovation and collaboration between different sectors of the creative industries.

2. One of the weaknesses of the case study projects was a limited correlation between a successful project and an actual increase in sales. More research might be done into this area of marketing in order to determine how authors might better convert online attention into higher book sales.

3. Another shortcoming of the projects was an element of risk and unpredictability inherent to the internet. These three projects enjoyed a great deal of online attention, but this was not guaranteed, and these projects may have easily been overlooked. Research may continue to be done into what causes a piece of online content to go "viral", and how to manage SEO and other factors in order to increase internet traffic to one's work.

\section{Bibliography}

Amazon (2015) Meatspace. Available at: http:// www.amazon.co.uk/Meatspace-Nikesh- Shukla/ dp/0007565062 (Accessed: 29 July 2015).

American Marketing Association (2014) Dictionary. Available at: https://www.ama.org/resources/Pages/Dictionary.aspx?dLetter=B (Accessed: 1 July 2015).

Arcade Fire: The Wilderness Downtown. Available at: http://www.thewildernessdowntown. com/\# (Accessed: 30 June 2015).

Armi Marketing (2011) How Should Your Brand Capitalize on Social Media? Available at: http://www.armi-marketing.com/library/ KnowledgePoint_SocialMedia.pdf (Accessed: 20 July 2015).

Baverstock, A. (2008) How to Market Books. 4th edn. London: Kogan Page.
Brace, I. (2004) Questionnaire design: how to plan, structure and write survey material for effective market research. London: Kogan Page.

Bury, L. (2013) 'Self-publishing boom sees 59\% increase in DIY titles', The Guardian. Available at: http://www.theguardian.com/books/2013/ oct/11/self-publishing-boom- increase-diy-titles (Accessed: 20 July 2015).

Charlotte Morrison-Reed (2007) Cost of a Culture: Publishing Practises and Financial Returns for Fiction and Nonfiction. Available at: http:// summit.sfu.ca/item/8404 (Accessed: 15 June 2015).

Chen, C-P. (2014) 'Forming digital self and parasocial relationships on YouTube', Journal of Consumer Culture, 0(0), pp. 1-23.

Chrome Experiments. Available at: https://www. chromeexperiments.com/arcadefire/ (Accessed: 30 June 2015).

Clifton, P. (2010) 'Teach Them to Fish: Empowering Authors to Market Themselves Online', Pub Res Q, 26, pp. 106-109.

Davies, J. (2012) Read This, It's Really Good: Word-of-Mouth Marketing In the Trade Publishing Industry. MA Publishing. University of the Arts London.

Davies, M. (2007) Doing a Successful Research Project: Using Qualitative or Quantitative Methods. London: Palgrave Macmillan.

Denzin, NK and Lincoln, Y S (eds) (2003) Collecting and Interpreting Qualitative Materials, New York, Sage.

Devaney, B.M. (2011) The Rest is Fetish, Is Popular, Is Waste: A study of the mid-list crisis and the implications for female authors. MA Publishing. University of the Arts London. 
Drass, E. (2013) 13 December. @klfbook. Available at: https://twitter.com/klfbook/ (Accessed: 30 June 2015).

Drass, E. (2013) @klfbook. Available at: http://www.shardcore.org/shardpress/index. php/2013/09/29/klfbook/ (Accessed: 30 June 2015).

Evans, D. (2012) Social Media Marketing. Sybex Inc. Available at: URL (Downloaded: 1 July 2015).

The First Bad Man Store: 50 Objects Mentioned in the Novel By Miranda July (2015) Available at: http://www.thefirstbadman.com/index.html (Accessed: 30 June 2015).

Genius (2015) 'That Thing When You're Canadian - Sheila Heti Goes Deep on the Great White North', Genius. Available at: http://memes.genius.com/post/120194363069/that- thing-whenyoure-canadian-sheila-heti-goes (Accessed: 22 June 2015).

Giuliano Long, T. (2013) Calling All \#Authors \& \#Bloggers for a Literary Road Trip. Available at: http://blog.tglong.com/2013/12/calling-authors-bloggers-literary-road-trip/ (Accessed: 30 July 2015).

Google (2015) Self-publishing book promotion. Available at: https://www.google.co.uk/webhp?sourceid =chrome-instant\&ion=1\&espv=2\&ie=UTF- 8\#q=self-publishing+book+promotion (Accessed: 20 July 2015).

Heaton Jones, L. (2010) An Investigation into Digital Marketing and Promotion within the Publishing Industry. MA Publishing. University of the Arts London.

Hermkens, K., Kietzmann, J., McCarthy I, Silvestre B. (2011) 'Social media? Get serious! Understanding the functional building blocks of social media', Business Horizons, 54(3), pp. 241-251.
Holmes, A. \& Parker, J. (2014) 'The Demands of Book Promotion: Frivolous of Necessary?', The New York Times. Available at: http://www. nytimes.com/2014/05/25/books/review/the-demands-of-book-promotion- frivolous-or-necessary.html?_r=0 (Accessed: 15 June 2015).

Internet Live Stats (2015) Number of Internet Users. Available at: http://www.internetlivestats. com/internet-users/ (Accessed: 1 July 2015).

Jones, C. \& Ryan, D. (2009) Understanding Digital Marketing: Marketing Strategies for Engaging the Digital Generation. Kogan Page. Available at: URL (Downloaded: 1 July 2015).

Kaplan, A. (2010) 'Users of the word, unite! The challenges and opportunities of social media', Business Horizons, 53(1),pp. 59-68.

Kinberg, M. (2014) 'Market Sensing as a Tool for Fiction Authors', Journal of Marketing and Management, 1(1), pp. 45-57.

Koosel, S.M. (2013) 'Artists and Digital Culture: (The Strain of) Self-Promotion in Social Media', Media Transformations Journal, 10.

Liberman, C.J. (2014) 'Branding as Social Discourse: Identity Construction Using Online Social and Professional Networking Sites', in Cunningham, C. (ed.) Social Networking and Impression Management: Self-Presentation in the Digital Age. Lanham: Lexington

Liu, M. (2014) 'Two worlds, two identities, one reality: Nikesh Shukla explores the impact of the internet on lonely lives', The Independent. Available

at: http://www.independent.co.uk/arts-entertainment/tv/features/two-worlds-two- identities-one-reality-nikesh-shukla-explores-the-impact-of-the-internet-on-lonely-lives- 9601178. html (Accessed: 2 August 2015).

Books, pp. 108-124. 
Lyle Skains, R. (2010) 'The Shifting Author-Reader Dynamic: Online Novel Communities as a Bridge from Print to Digital Literature', Convergence, 16(1), pp. 95- 111.

Marosevic. K (2014) 'Is the mid-list, "publishing's experimental laboratory," disappearing?, Melville House Books. Available at: http://www. mhpbooks.com/is-the- mid-list-publishings-experimental-laboratory-disappearing/ (Accessed: 22 June 2015).

Medley, M. (2015) 'Anatomy of a Merger: Penguin Random House Canada', The Globe and Mail, 27 June.

Mintel Academic (2014) 'Executive Summary - Books and ebooks - UK - September 2014'. Available at: http://academic.mintel.com/display/679475/ (Accessed: 22 June 2015).

Morris, J. (2011) 'Will eBooks Make Midlist Authors Extinct?', The Huffington Post. Available at: http://www.huffingtonpost.com/ james-mcgrath-morris/will-ebooks-makemidlist_b_606572.html (Accessed: 22 June 2015).

Nelson, S. (2005) 'Author, Sell Thyself', Publisher's Weekly, 252(39), p. 7.

Parks, T. (2015) Where I'm Reading From: The Changing World of Books. New York: New York Review Books.

Pham, A. (2010) Book publishers see their role as gatekeepers shrink. Available at: http://articles. latimes.com/2010/dec/26/business/la-fi-gatekeepers-20101226 (Accessed: 20 July 2015).

Placing Literature (2013) Bestselling Author Uses Location to Reach New Readers. Available at: https://placingliterature.wordpress.com/tag/ book-promotion/ (Accessed: 29 July 2015).
Placing Literature (2013) Literary Road Trip with Placing Literature. Available at: https:// placingliterature.wordpress.com/2013/12/09/ literary-road-trip-with-placing- literature/ (Accessed: 16 August 2015).

Rankin, J. (2014) 'Publish and be branded: the new threat to literature's laborator', The Guardian. Available at: http://www.theguardian. com/books/2014/jan/13/publish-brand- literature-hilary-mantel-jk-rowling (Accessed 22 June 2015).

Research Proposals for Health Professionals (2015) Definition of Quantitative Research. Available at:

http://www.researchproposalsforhealthprofessionals.com/definition_of_quantitative_rese a.htm (Accessed: 28 July 2015).

Robinson, C. (2014) 'The Loneliness of the Long-Distance Reader', The New York Times. Available at: http://www.nytimes. com/2014/01/05/opinion/sunday/the-loneliness- of-the-long-distance-reader.html?_r=1 (Accessed 22 June 2015)

Romeyer, C. (2012) How are Social Media Platforms Being Used in the Marketing of Events in the Publishing Industry. MA Publishing. University of the Arts London.

Rooney, M. (2014) 'Kindle Direct Publishing (KDP) - Reviewed', The Independent Publishing Magazine. Available at: http://www.theindependentpublishingmagazine.com/2014/02/ kindle-direct- publishing-kdp-reviewed.html ((Accessed: 20 July 2015).

Sargent, B.K. (2014) 'Brand Yourself for Indie Success', Publishers Weekly, 261(30), p. 40.

Seibold, M. (2010) An Investigation into Social Media as a Tool to Enhance the Marketing Communications Mix in the UK Consumer Book Publishing Industry. MA Publishing. University of the Arts London. 
Seidlinger, M. (2014) 'The Fun We're Supposed to Be Having', Electric Literature. Available at: http://electricliterature.com/the-fun-were-supposed-to-behaving/ Accessed: 9 July 2015).

Sheehan, B. (2010) Basics Marketing 02: Online Marketing. AVA Publishing. Available at: URL (Downloaded: 1 July 2015).

Shields, R. (2013) 'Facebook introduces hashtags', Marketing Week, p. 5.

Shukla, N. (2014) 'Exclusive: Why I Just Sent a Lamb Chop into Space', Vice. Available at: http:// www.vice.com/en_uk/read/i-sent-a-lambchopinto-space-to-promote-my-book- 237 (Accessed: 29 July 2015).

Shukla, N. (2015) Nikesh Shukla. Available at: http://www.nikesh-shukla.com/ (Accessed: 2 August 2015).

Shukla, N. (2014) Tandoori Lambchop Sent to Space (Meatspace). Available at: https://www. youtube. $. \mathrm{mm} /$ watch?v=6E1 NoGAs6wM (Accessed: 11 August 2015).

Slatter, A. (2014) 'Online Presence: Pros, Perils and Possibilities', The Writing Platform. Available at: http://www.thewritingplatform. com/2014/12/online-presence-pros-perilsand-possibilities/ (Accessed: 22 June 2015).

Smith, R. (2015) 'How to publish a book in Canada', The Globe and Mail, 4 July.

Statista (2015) Number of monthly active Facebook users worldwide as of 2nd quarter 2015. Available at: http://www.statista.com/statistics/264810/number-of-monthly-active- facebook-users-worldwide/ (Accessed: 1 July 2015).

Statista (2015) Number of monthly active Twitter users worldwide from 1st quarter 2010 to 2nd quarter 2015. Available at: http://www.statista.com/statistics/282087/number-of- monthly-active-twitter-users/ (Accessed: 1 July 2015).
Strugatz, R. (2014) 'Social Media Sites Gain in World of Digital Ads', WWD: Women's Wear Daily, 207(13), p. 1.

Thompson, J. (2012) Merchants of Culture. 2nd edn. Cambridge: Polity Press. Trubek, A. (2012) 'Why Authors Tweet', The New York Times. Available at:

http://www.nytimes.com/2012/01/08/books/review/why-authors-tweet.html (Accessed: 15 June 2015).

Valand, H. (2012) How do Publishers Use Interactive Marketing Communications Channels to Promote Young Adult Fiction Within the Contemporary Teenage Media Consumption Landscape. MA Publishing. University of the Arts London.

Wagner, K. (2011) 'The History of Amazon's Kindle So Far', Gizmodo. Available at: http://gizmodo.com/5844662/the-history-of-amazons-kindle-so-far (Accessed: 20 July 2015)

Yin, R. (2009) Case Study Research: Design and Methods. 4th edn. Thousand Oaks: SAGE Publications.

Zhang, Y \& Wildemuth B. (2009) Qualitative Analysis of Content. Available at: https://www. ischool.utexas.edu/ -yanz/Content_analysis.pdf (Accessed: 28 July 2015). 